\title{
Stability analysis and remedial design of two road cuttings in North Queensland based on remote geotechnical mapping using digital photogrammetry
}

\author{
I. Ortega Golder Associates Pty Ltd, Australia \\ P.W. Booth Golder Associates Pty Ltd, Australia \\ J. Darras Golder Associates Pty Ltd, Australia
}

\begin{abstract}
Remote geotechnical mapping of two large rock cuttings on a vital transportation corridor in North Queensland was undertaken to provide input data for stability analysis and design of stabilisation elements. The mapping approach described utilised state-of-the-art digital photogrammetry tools to allow the collection of structural data from large areas where direct access to the slopes for conventional (tape measure and compass) mapping was either not possible or very limited without the use of rope access methods.
\end{abstract}

The photogrammetric method employed allowed the mapping to be completed rapidly and safely, without affecting the serviceability of the roadway during the site investigation. It provided measurements of the orientation, spacing and persistence of the rock discontinuities that control the stability of the cuttings. It also provided detailed digital terrain models (DTMs) of the slopes, which provided critical topographic information for input to the analysis and design processes.

In recent years, the use of digital photogrammetry as a tool to collect structural and geotechnical mapping data from large rock cuttings has become commonplace in the mining industry. The application of this method to civil engineering problems on the other hand has been far less common, but comes as a natural progression as this technology becomes more user-friendly and cost-effective.

\section{Introduction}

Captain Cook Highway is the main transportation corridor connecting the northern populations of coastal Queensland. It is used daily by many tourists to travel between Port Douglas and Cairns. The road construction began in 1930, and was completed by 1934, with the associated limitations on slope analysis capabilities and in the excavation machinery of that time. As a consequence of this, many of the current slopes along the highway probably present Factors of Safety close to unity. The Queensland Government edited in 2010 a Concept Design Report (Queensland Government, 2010) containing many references to recent and past slope failures which have affected the carriageway. The most important event is probably the big volume failure which happened in Ellis Beach on 12 January 1951. A deluge of about $700 \mathrm{~mm}$ of rain in just under five hours triggered debris flows that affected $10 \mathrm{~km}$ of the highway. Boulders up to three metres long were hurled into the Pacific 'like marbles' (Michael-Leiba et al., 2007).

The Rex Lookout and Yule Point sites, located north of Cairns and close to the village of Port Douglas, have been recently affected by episodes of rock block detachments and large volume instabilities. A detailed assessment on the slopes of these two sites has been undertaken as part of the design of the mitigation measures. The difficulties in accessing most of the slope surface in both sites didn't permit the measuring and recording of the required geotechnical data for the design except for in limited areas.

Terrestrial photogrammetric methods were therefore employed to undertake the mapping remotely, using the 3DM analyst mine mapping suite software (ADAM Technology, 2013). The use of this method provided several benefits over rope access methods, including more rapid data collection, greater mapping coverage 
of otherwise inaccessible areas, the provision of accurate topographic profiles for use in the analysis and design process, and improved safety by eliminating or reducing the need for physical access to the slope. This paper summarises the learnings acquired from this experience, along with a brief description of the major failure mechanisms, and how the use of a Digital Terrain Model has helped the analysis and the remedial works design.

\section{Remote geotechnical mapping using digital photogrammetry}

Digital photogrammetry is the science of determining the three-dimensional (3D) locations of objects from 2D digital photographs. It has been referred to as the fourth epoch in the history of photogrammetry's development; being preceded by plane table photogrammetry (1850-1900), analogue photogrammetry (1900-1960), and analytical photogrammetry (1960-1990s) and digital photogrammetry (Spring, 2012).

Digital photogrammetry uses digital photographs of a scene captured from two or more different locations (i.e. 'stereo pairs'), in the same way the human eye does, in order to perceive depth and dimension of space. By locating common points in both images (or groups of images), modern photogrammetric software can automatically calculate the 3D location of a very large number of points in the scene and use this information to automatically generate a digital terrain model (DTM). When coupled with the known location of a small number of control points in the scene, the DTM can be georeferenced and the user is able to digitise and measure any feature that can be seen in at least two images; to an accuracy of around 1:10,000 of the size of the area covered by a single image (ADAM Technology, 2010).

In the case of the Rex Lookout and Yule Point, photography for both sites was captured using an Unmanned Aerial Vehicle Survey, owned and operated by a specialised aerial photography contractor. Use of the UAV provided benefits in cost, safety and logistics as compared with using a conventional helicopter. Figure 1 shows the UAV which was used in both sites.

An array of ground control targets were established on the site prior to undertaking the photography, at strategic locations designed to provide an even 3D spread across the scene being modelled. The locations of the targets were then surveyed and the coordinates were provided to Golder for input at the processing stage.

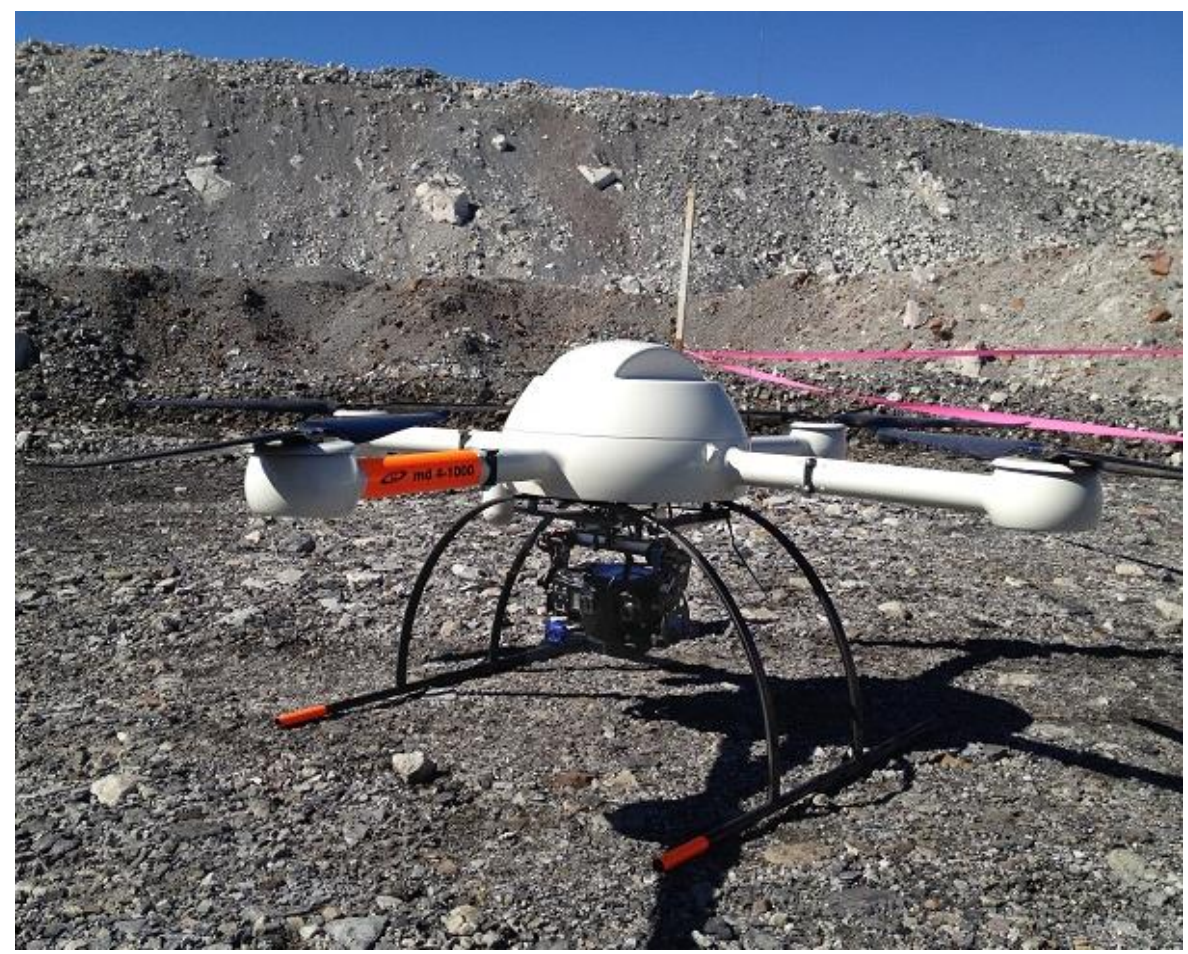

Figure 1 Unmanned Aerial Vehicle (UAV) used in both investigations (courtesy of Helimetrex Pty Ltd) 
The photographs and ground control survey information were imported into the 3DM analyst software and used to generate a series of DTMs covering the areas of interest. The DTMs were then used to undertake mapping of the orientation, spacing, persistence and large scale waviness of defects exposed in the pit walls. This was undertaken using the geotechnical mapping tools provided within the software.

\section{The Rex Lookout slope}

\subsection{Investigated area}

The Rex Lookout site is located on the Captain Cook Highway just north of the Rex Lookout about $40 \mathrm{~km}$ north of Cairns. Rock exposed in the cuttings and natural outcrops in the area is mapped as late Permian aged Wangetti Granite (1:100,000 Geological Map of the Cairns Region, Sheet 8064 and Part Sheet 8063).

Rock exposed in the near-vertical road cutting contains joints that intersect to form high strength rock blocks up to $5 \mathrm{~m}$ across. A prominent exfoliation (stress relief) joint oriented sub-parallel to the natural surface dips out of the cutting, and extends to form the natural ground surface to the north of the site. The rock in the cutting was apparently damaged by overcharging blast holes during the original construction. The ground surface north of the cutting is interpreted to have formed as a result of a landslide controlled by the extension of the exfoliation joint in the cutting. The photo in Figure 2, taken immediately following heavy scaling of loose rock blocks, illustrates these geometric conditions.

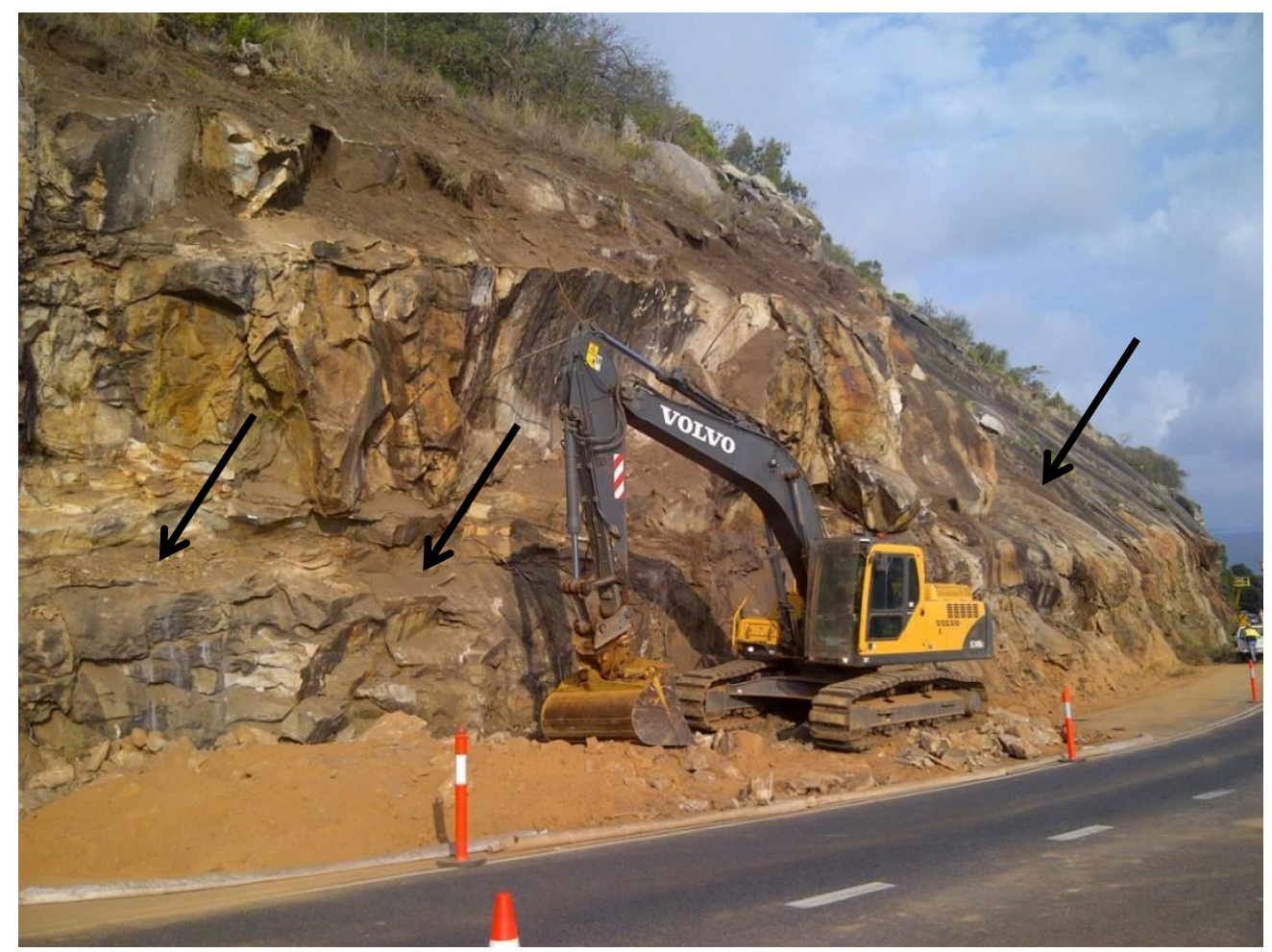

Figure 2 View of the northern section of the Rex Lookout site. The exfoliation joint exposed in the cutting extends to form the natural ground surface to the rear of the excavator

\subsection{Analysis of the potential planar failure}

The potential for a planar failure mechanism is evident by simple inspection of Figure 2. Figure 3 provides the stereographic representation of the main joint defects. The kinematic admissibility of the planar failure is quickly revealed by the undertaking of a classical static analysis. The planar failure was assessed by means of a static equilibrium calculation. An initial geometry of the failure was disclosed by comparing cross sections from different chainages of the site. To illustrate this, Figure 4 shows a superposition of two cross-sections, along with a basic sketch of the failure mechanism with indication of some of the parameters with an influence on the resulting Factor of Safety. 


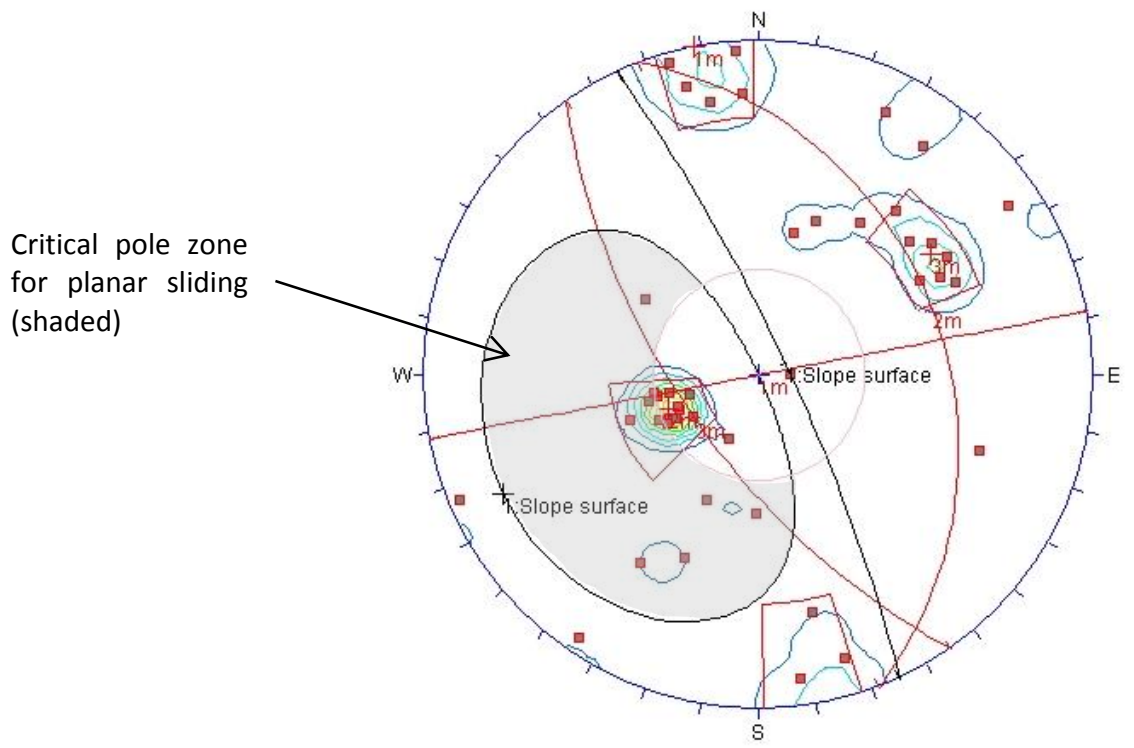

Figure 3 Stereographic projection view of the rock discontinuities in one section of the Rex Lookout site. The potential a planar failure is highlighted

Some of the parameters that were required for the calculations and design were deduced or corroborated using the data provided by the DTM. A statistical analysis and a sensitivity analysis on the basal joint dip angle, which had a remarkable influence on the resulting Factor of Safety, was carried out based on the DTM survey information.

Furthermore, the shear strength of the rock joints was also assessed with the aid of the generated information, as explained in the following.

The shear strength has been estimated using the classical non-linear approach by Barton and Choubey (1977):

$$
\tau=\sigma_{n} \tan \left(\phi_{r}+J R C \log _{10}\left(\frac{J C S}{\sigma_{n}}\right)\right)
$$

Where:

$\sigma_{n} \quad=$ normal stress on the joint.

$J R C=$ Joint Roughness Coefficient.

$J C S=$ Joint Compression Strength.

$\Phi_{r} \quad=$ residual angle of friction, which can be calculated from the basic angle of friction of the joint as (Barton and Choubey, 1977).

$$
\phi_{r}=\left(\phi_{b}-20\right)+20(r / R)
$$

Where:

$\Phi_{b} \quad=$ basic angle of friction.

$r \quad=$ Schmidt rebound number on wet and weathered fracture surfaces.

$R=$ Schmidt rebound number on dry unweathered sawn surfaces. The slight weathering of the joints suggested that equalling the basic to the residual friction angle was an acceptable assumption for the site. 

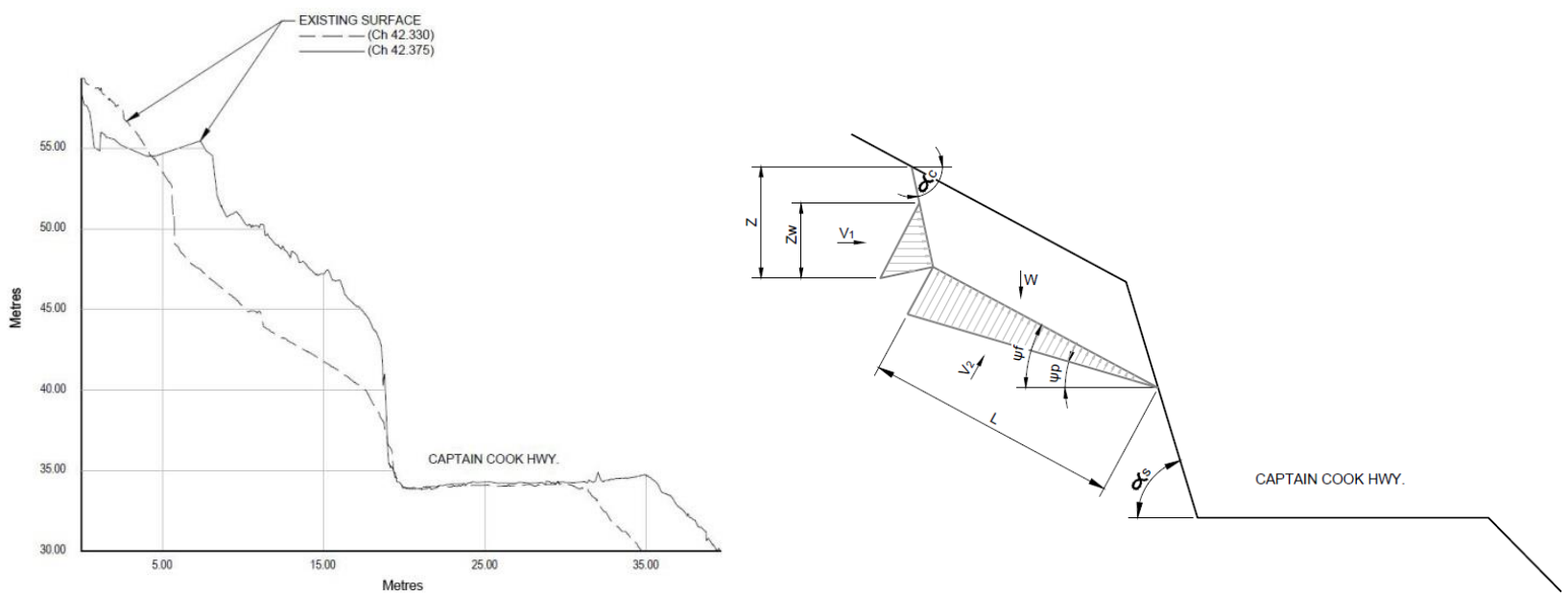

Figure 4 Approximate determination of the planar failure mechanism in the Rex Lookout site by comparison of two cross sections, and sketch of the simplified geometry with some of the parameters with influence in the resulting Factor of Safety

$\Phi_{b}$ was estimated based in published technical literature (Barton and Choubey, 1977). JCS was deduced from site tests and a review of the available data on local geology. JRC was deduced from analysing both field measures and DTM information on the asperity amplitudes in different joint profiles.

Figure 5 shows the location of one of the spots where the joint roughness was assessed, which corresponds to the basal joint surface. The digital disk is oriented parallel to (local orientation) and on the joint in question. A detailed view of the joint surface is also presented in the same figure. Figure 6 shows a 3D view of the surface topology of the exposed joint surface, and a profile of the basal joint selected in Figure 5.

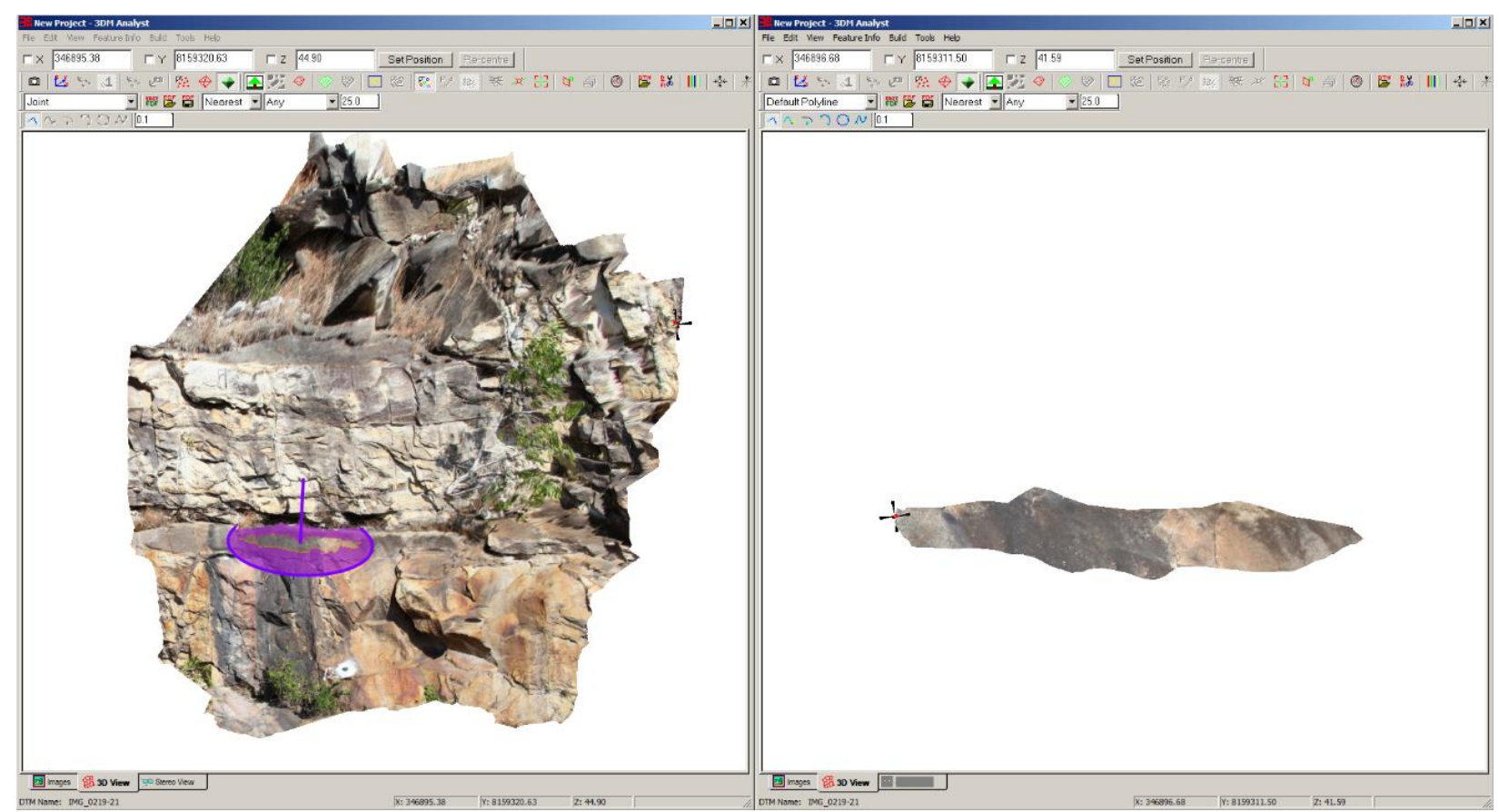

Figure 5 Location of one of the spots where the basal joint is exposed

From this result, JRC can be estimated using the measurements of surface roughness amplitude from a straight edge (Hoek, 2007). As an example, the central section $(0.2$ to $0.9 \mathrm{~m})$ of the profile in Figure 6 would provide a roughness amplitude close to $15 \mathrm{~mm}$, which would lead to JRC in the order of 10. 
Summarising the previous results, Figure 7 presents the graphic representation of Equation 1 for one set of parameters included in the sensitivity analysis approach. A linear stress relation is derived by drawing a tangent to the Barton-Choubey non-linear curve at the estimated normal stress acting on the basal joint.
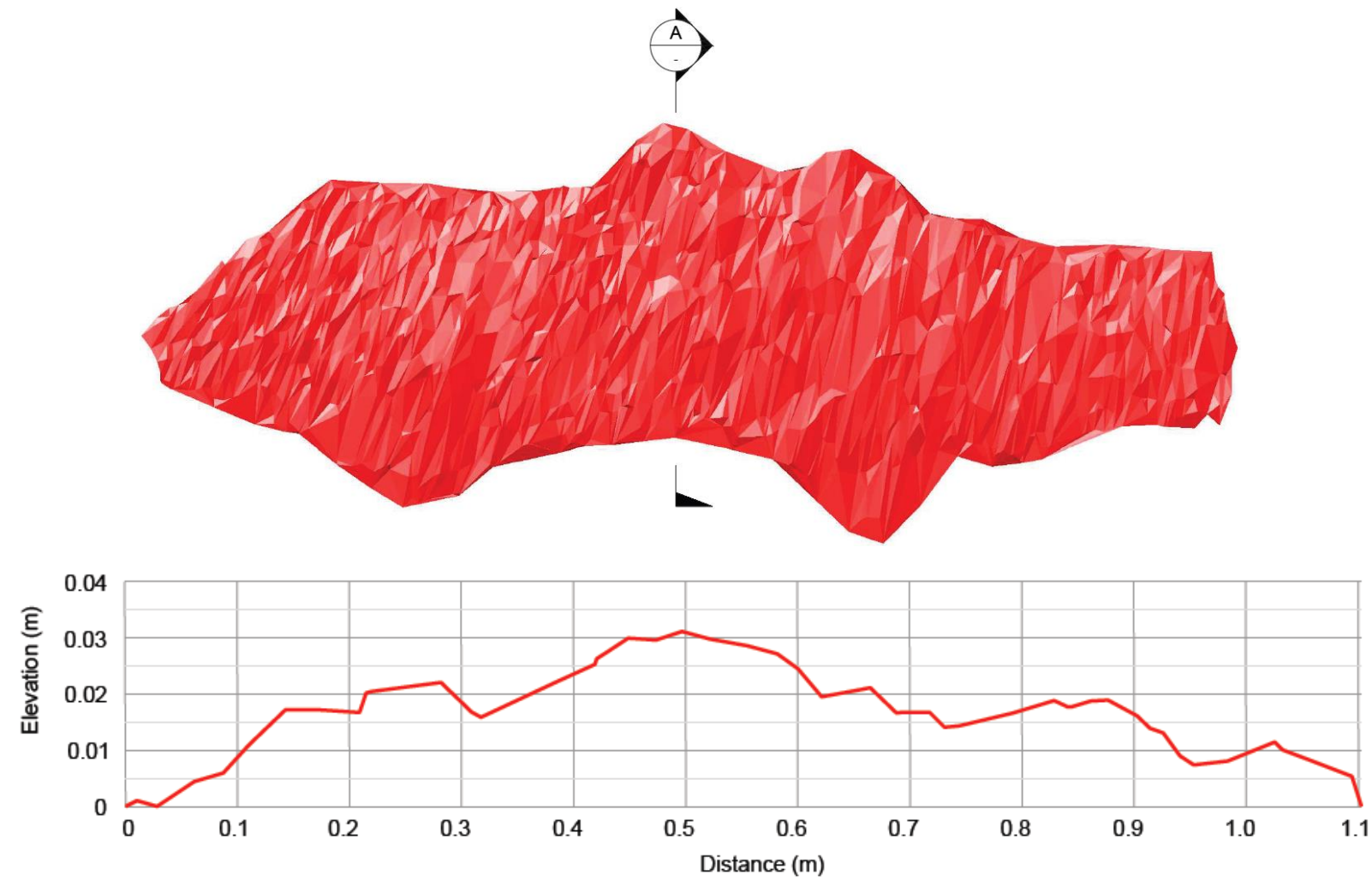

Figure $63^{D}$ view of the joint highlighted in Figure 4 and cross profile in the direction of the probable failure movement (section A)

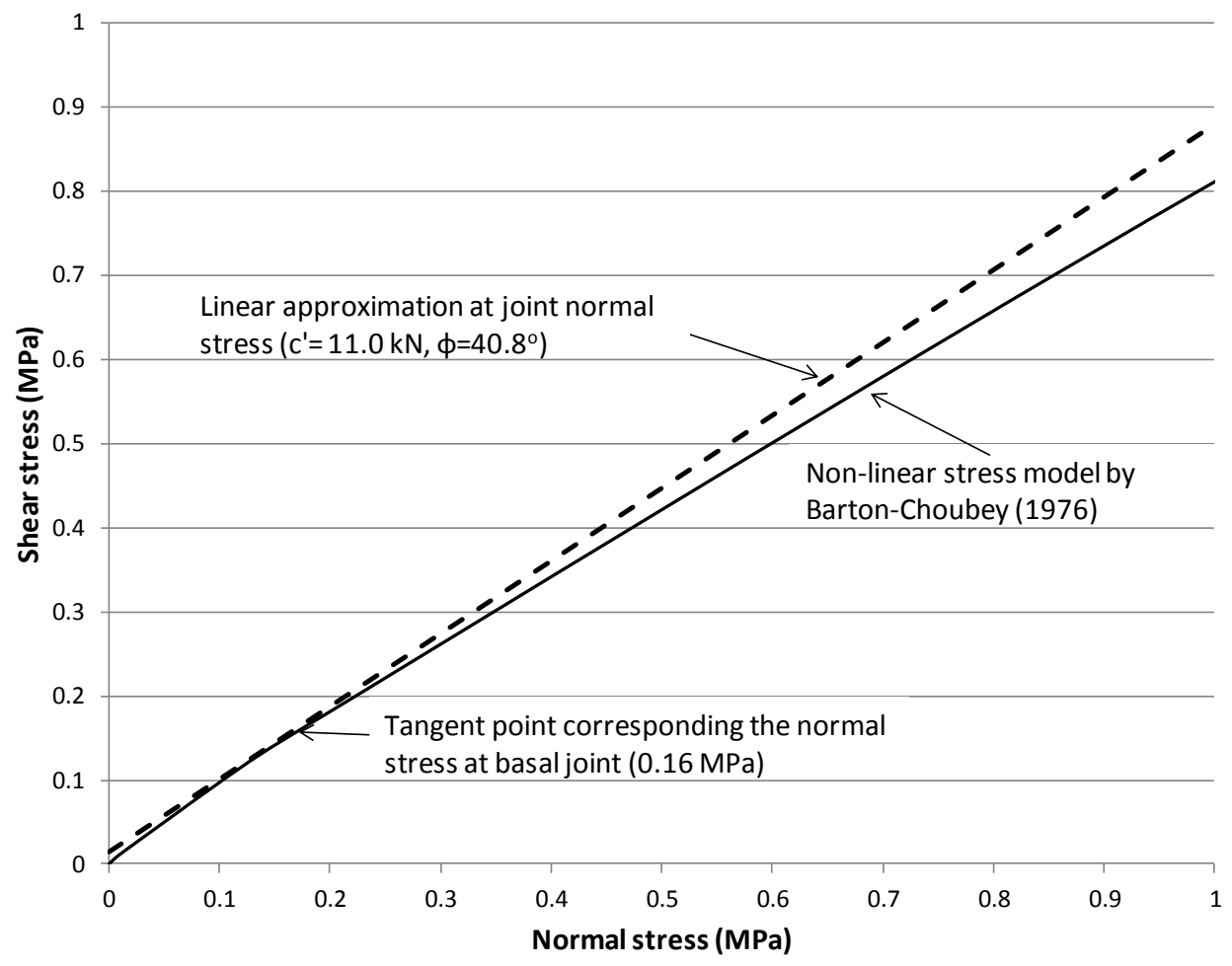

Figure 7 Linear approximation of the non-linear stress relation (Barton and Choubey, 1977) at the mean normal stress acting on the basal joint 


\subsection{Investigated area}

The Yule Point site is located just north of Pebble Beach and about $12 \mathrm{~km}$ south of Port Douglas. Regional mapping indicates that the site is underlain by Devonian age Hodgkinson Formation. Hodgkinson Formation rocks are described as variably metamorphosed sedimentary rocks consisting of argillite, quartzite, mica schist, phyllite, greywacke, arenite with occasional bands of marble. Rocks exposed on site are predominantly consistent with the regional mapping, although it appears that the lower part of the cutting is more intensely metamorphosed and less weathered. The foliation partings in the metasedimentary rocks, the predominant structural feature on site, dip steeply $\left(50\right.$ to $\left.60^{\circ}\right)$ toward the southwest, consistent with regional mapping. Joints dipping out of the slope intersect with the foliation to form medium to high strength blocks up to about $6 \mathrm{~m}$ in maximum dimension and ledges with overhanging faces. Figure 8 presents a view of the site generated by the photogrammetry data.
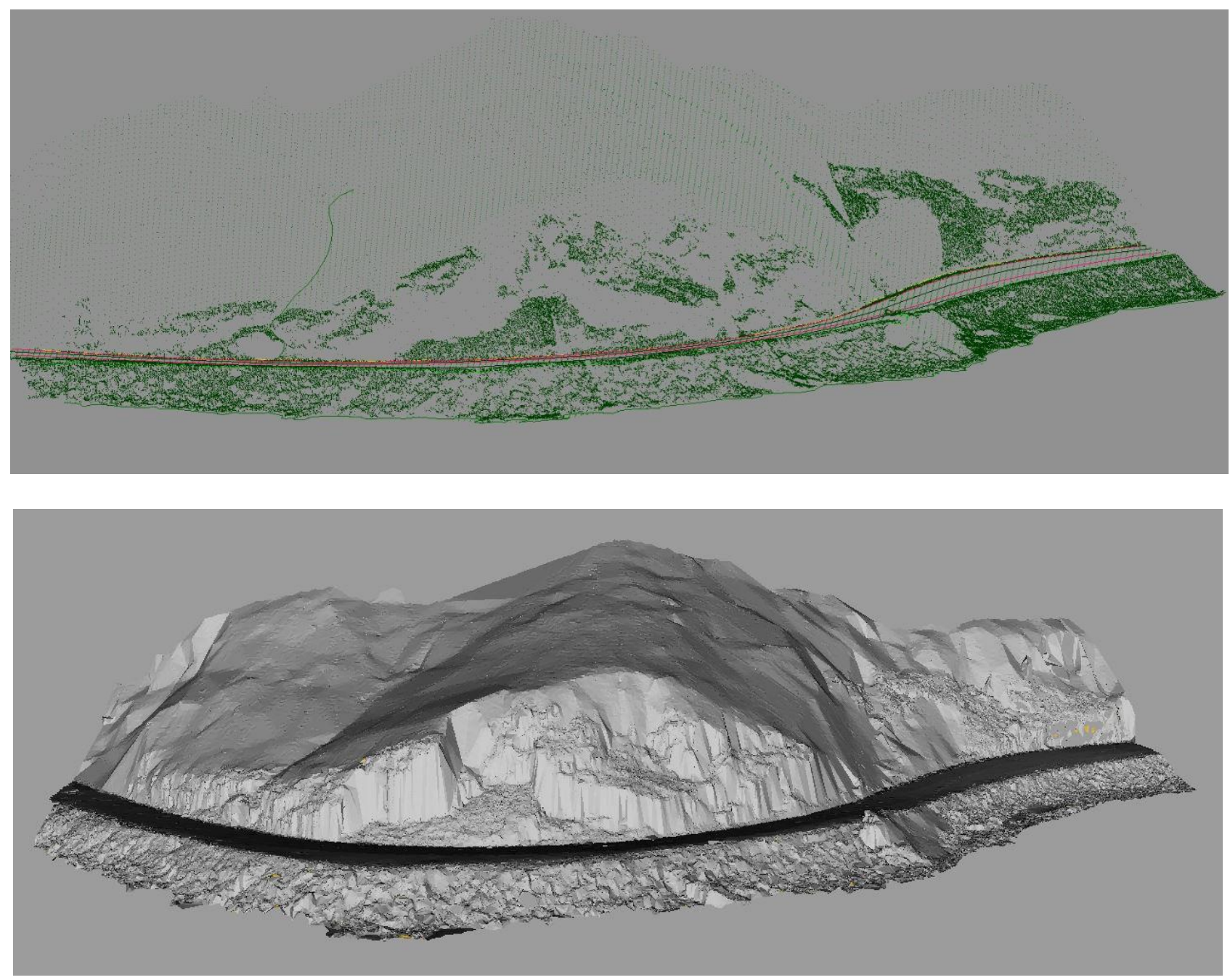

Figure 8 View of the Yule Point site as deduced from the DTM information (point cloud and surface model)

\subsection{Analysis of the toppling failure mechanism}

The configuration of the rock joints in this area provides the geometric conditions for a toppling failure mechanism to occur. Figure 9 presents a view of the cuttings in the middle section of the site. The potential for toppling failures is evident by simply noting the height and the dip angle of the unsupported rock slabs that configure the lower levels of the slope surface. 
The potential for the toppling mechanism is confirmed by the stereographic projection of the rock joints in Figure 10. The possibility of a toppling failure is evident from a static analysis of the joint spatial distribution.

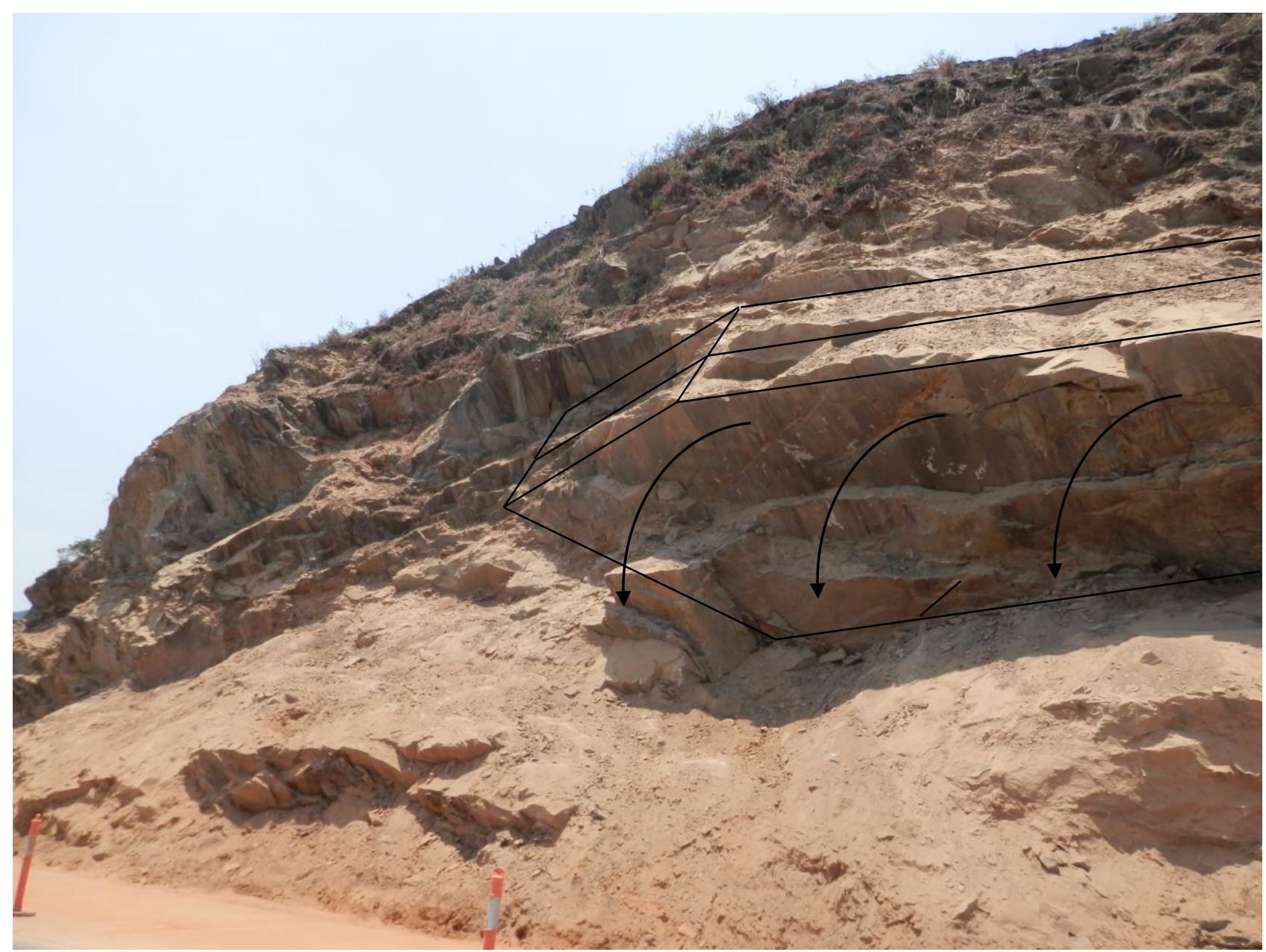

\section{Figure 9 Example of the geometry of Yule Point cuttings. The boundaries of the first slices} involved in a probable topping mechanism are indicated in black lines

The toppling mechanism has been assessed by means of the classical approach by Hoek and Bray (1981). The basic parameters of this analysis are the shear capacity of the joints (cohesion and friction angle) and the geometry of the discontinuities (dip direction, dip angle and joint spacing). Figure 11 presents a basic definition of the toppling mechanism corresponding one of the assessed cross-sections.

The mapping of the DTM has provided useful information for a more accurate definition of the as found conditions, to be used in the detailed stability assessment and development of design recommendations. Apart from the determination of the Mohr-Coulomb shear resistance parameters, which is broadly discussed in the Rex Lookout chapter, the data generated by the model provides valuable geometric information.

To illustrate this, Figure 12 shows the simplified geometric model of one cross section that was considered in the analysis. The main parameters with an influence in the evaluation of the Factor of Safety are indicated in the figure. Most of them can be checked or derived from the information provided by the DTM.

As expected, the stability analysis of this mechanism revealed that one of the key parameters influencing the resulting Factor of Safety is the width of the rock slabs involved in the toppling. Figure 13 presents the histogram of the measured joint spacing data obtained from the photogrammetric mapping. This histogram can be used to assign a design value based on a risk assessment of the slope. 


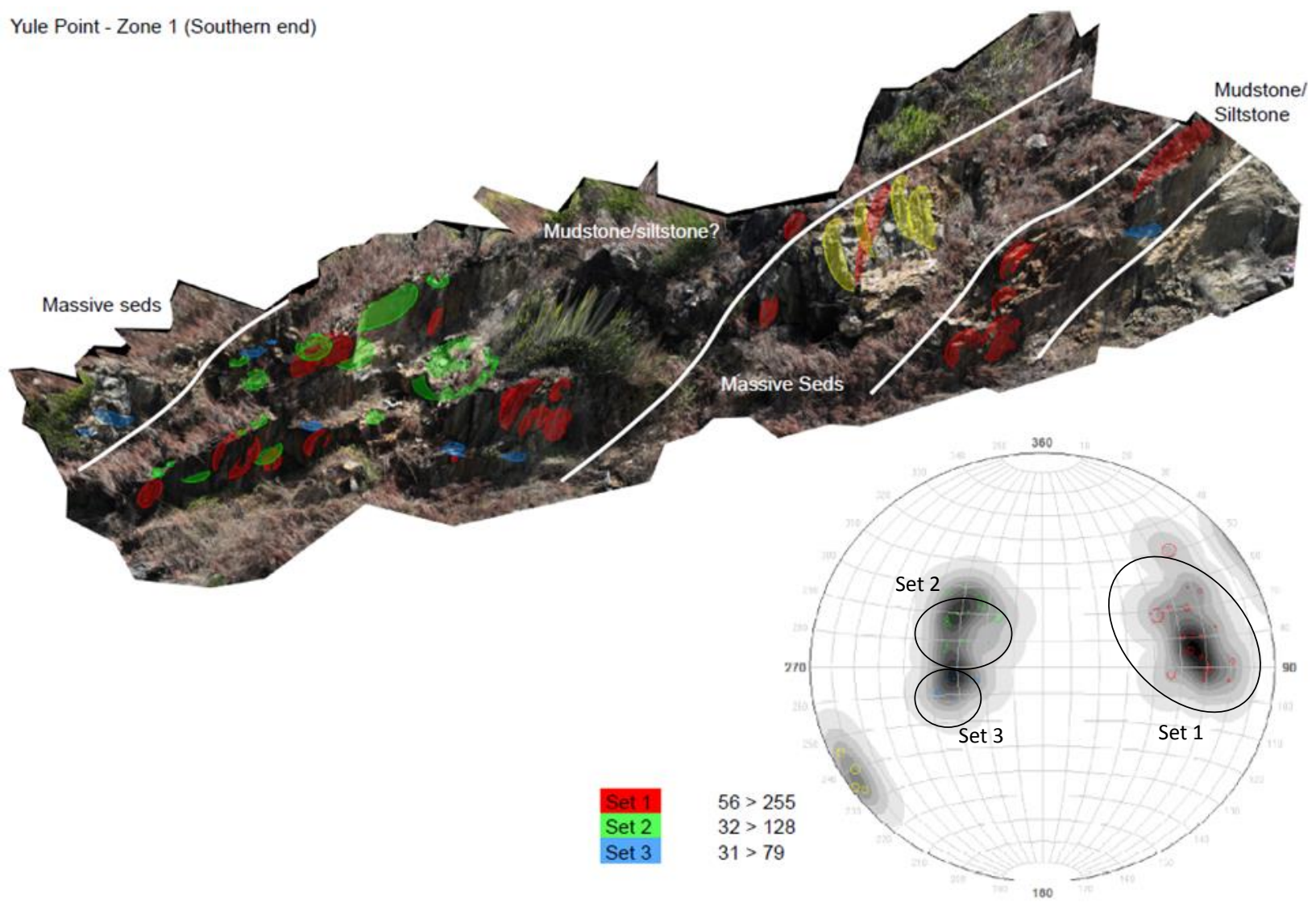

Figure 10 General view of one of the sections on Yule Point site. Stereographic projection of the main joints in the area is also indicated

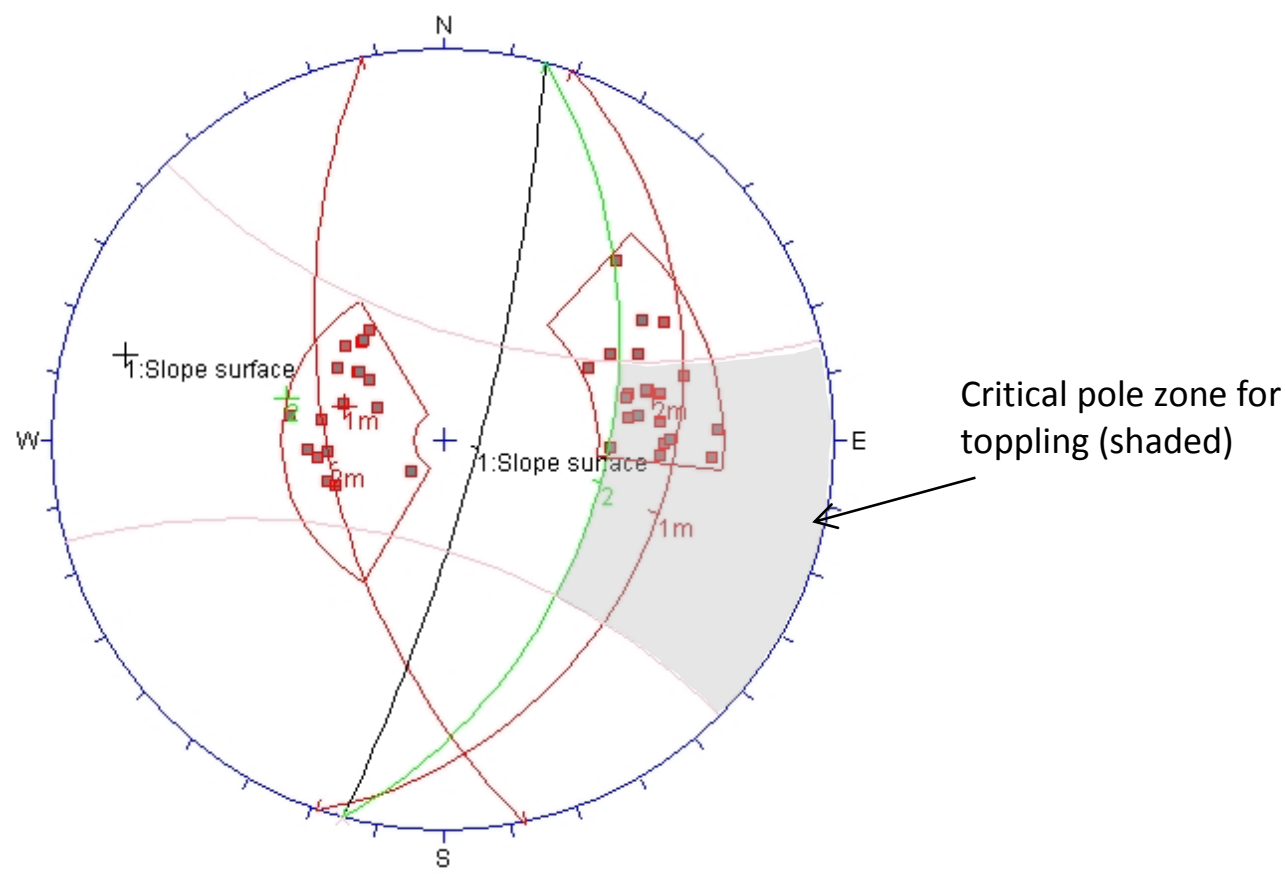

Figure 11 Detailed stereographic projection of the rock discontinuities in the same area as Figure 10. The risk of a toppling failure is highlighted 


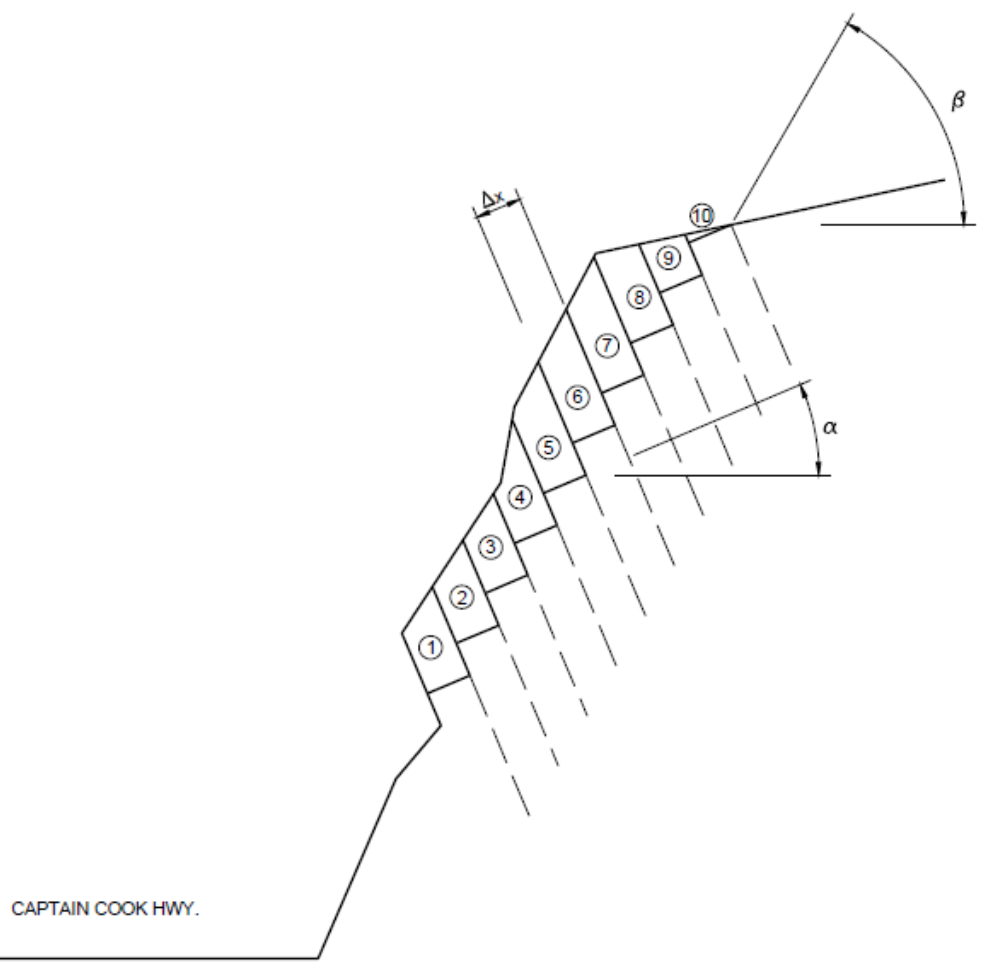

Figure 12 Example of a simplified geometry of a toppling mechanism used to model one of the Yule Point analysis cross sections. Key geometric parameters are indicated $(\Delta x$, spacing of discontinuities; $\alpha$, dip of basal joint; $b$ mean failure dip angle)

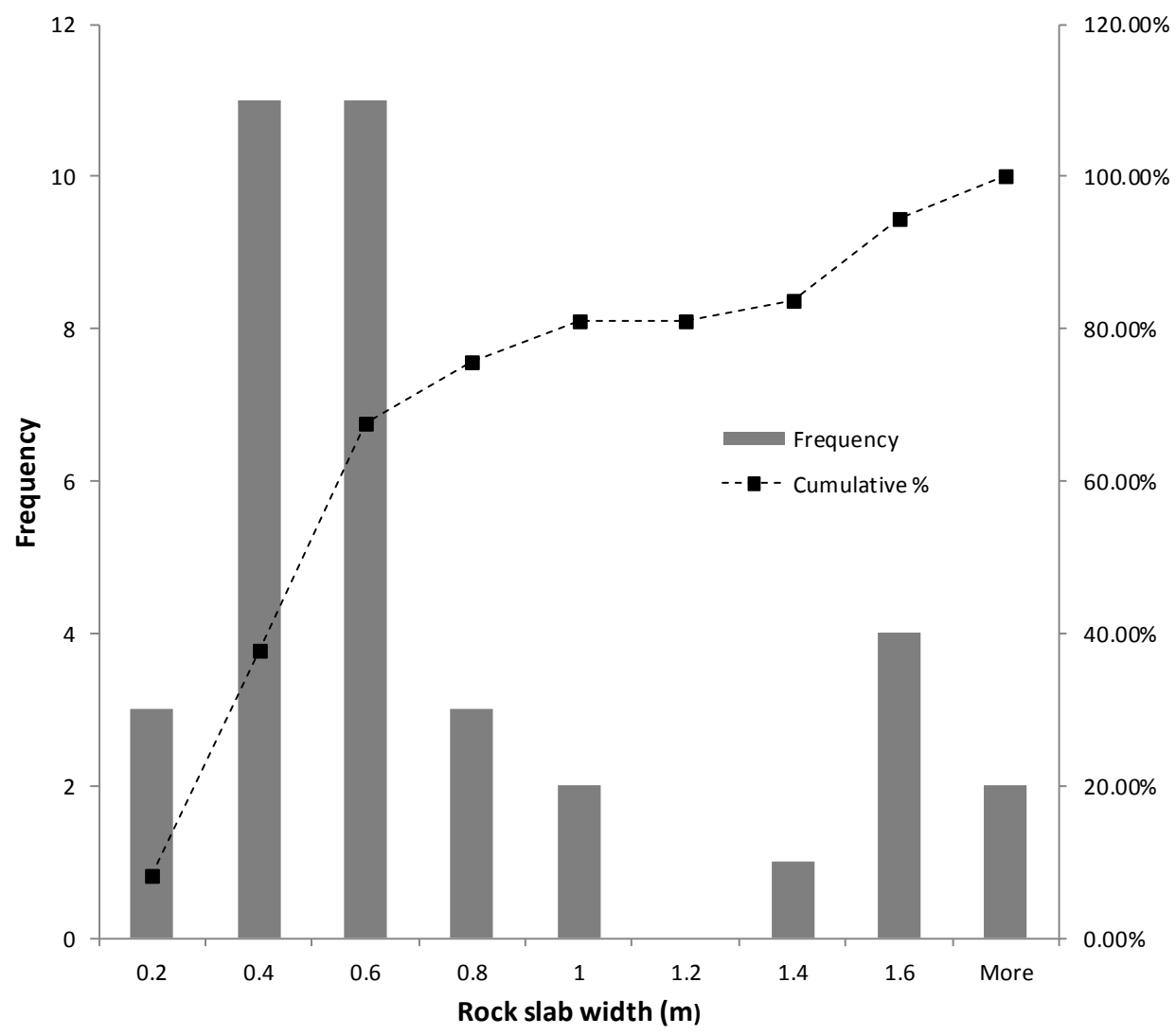

Figure 13 Histogram of the rock joint spacing at the section on Figure 10 (Set 1). Data provided from the DTM 


\section{$5 \quad$ Conclusions}

The benefits of using digital photogrammetry in the slope stability analysis of two complex cuttings in the Captain Cook Highway have been exposed. The assets of this technology include the ability to measure representative rock discontinuities rapidly and safely, regardless of their location. Accurate information on spacing and location of the joints can be obtained, with greater density of data than conventional mapping. These features provide the geotechnical engineer with a remarkable amount of information to complete a very accurate and statistically valid design of the remediation measures.

Digital photogrammetry is a highly adaptable and versatile tool, with a wide range of applications across a range of industry sectors and technical disciplines. Though traditionally used in mining developments and some times in the design of big civil infrastructures, the recent developments of the data acquisition systems and of new simpler user-friendly data management software will undoubtedly help to generalise the use of these techniques in common engineering analysis problems.

\section{Acknowledgement}

The authors thank Helimetrex Pty Ltd for the information provided on the DTM models and on the description of the technology.

\section{References}

ADAM Technology (2010) 3DM Analyst Mine Mapping Suite User Guide, 378 p.

ADAM Technology (2013) 3DM Analyst Mine Mapping software, http://www.adamtech.com.au/3dm/Analyst.html.

Barton, N.R. and Choubey, V. (1977) The shear strength of rock joints in theory and practise, Rock Mechanics, Springer Verlag, Vol. 10(1-2), pp. 1-54.

Hoek, E. and Bray, J.W. (1981) Rock slope engineering, The Institution of Mining and Metallurgy, CRC Press, London, UK, 368 p.

Hoek, E. (2007) Practical Rock Engineering, viewed 9 August 2013, http://www.rocscience.com/.

Michael-Leiba, M., Granger, K. and Scott, G. (2007) Landslide risk in Cairns, Australian Emergency Management, Attorney-General's Department, viewed 9 August 2013, http://www.em.gov.au/Documents/Landslide\%20Risk\%20and\%20Cairns.pdf.

Queensland Government (2010) Concept Design Report, chapter 9, Ground Conditions, viewed 9 August 2013, http://www.tmr.qld.gov.au/ /media/Projects/C/Cairns\%20Transit\%20Network/Alignment\%20Plans/Concept\%20Design\%2 OReport/chapter09_ground_conditions.pdf.

Spring, A.P. (2012) Digital Photogrammetry and ADAM Technologies, GEO Informatics Magazine, Vol. 15, June 2012 , pp. 18-21. 
Stability analysis and remedial design of two road cuttings in North Queensland based on remote

I. Ortega et al. geotechnical mapping using digital photogrammetry 